\title{
Comparison of Time Development of the Sciatic Nerve Blockade Performed with 1\% Lidocaine Subgluteal and Popliteal Approach under Ultrasound Guidance
}

\author{
Piacherski Valery*, Marachkou Aliaksei, Brukhnou Andrei, Zakhar Kokhan \\ Department of Anesthesiology and Intensive Care, Health Care Institution "Mogilev Regional Hospital", \\ Mogilev, Republic of Belarus \\ Email: "pechersky.v@yandex.ru
}

Received 6 October 2014; revised 21 November 2014; accepted 22 December 2014

Copyright (C) 2014 by authors and Scientific Research Publishing Inc.

This work is licensed under the Creative Commons Attribution International License (CC BY).

http://creativecommons.org/licenses/by/4.0/

(c) (i) Open Access

\section{Abstract}

The existing researches in the field of regional anesthesia of the sciatic nerve show that if popliteal sciatic nerve blockade is performed, the time of the development of the sciatic nerve anesthesia is longer in comparison with subgluteal sciatic nerve blockade. Background: The aim of the research is to compare the time of the development of the sciatic nerve blockade performed with $1 \%$ lidocaine with epinephrine $(1: 200,000)$ in subgluteal and popliteal areas under ultrasound guidance. Materials and Methods: Patients were divided into two groups. In Group A (20 patients), the subgluteal approach to block the sciatic nerve was taken; in Group B (20 patients), the popliteal approach was applied. All blockades of the sciatic nerve were performed with $1 \%$ lidocaine $(30 \mathrm{ml}$ of lidocaine with epinephrine $(1: 200,000))$ and electrical stimulation of peripheral nerves under ultrasound guidance. We measured the time of the development of sensory and motor blocks. Results: In Group A, the sciatic nerve sensory block developed in 15 (14 - 16) minutes, a complete motor block developed in 15.5 (15 - 17) minutes. In Group B the sciatic nerve sensory block developed in 40 (38.5 - 42.5) minutes while a complete motor block did not develop in any patient. Conclusion: When the sciatic nerve is blocked in subgluteal area with $30 \mathrm{ml}$ of $1 \%$ lidocaine with epinephrine $(1: 200,000)$ under ultrasound guidance, sensory blocks develop faster than during the popliteal blockade: $15(14$ - 16) minutes vs. 40 (38.5 - 42.5) minutes respectively. The opportunity to define the place of the introduction of local anesthetic in our research is limited.

\section{Keywords}

Blockade of the Sciatic Nerve, Lidocaine, Subgluteal Approach, Popliteal Approach, Ultrasound

\footnotetext{
"Corresponding author.
}

How to cite this paper: Valery, P., Aliaksei, M., Andrei, B. and Kokhan, Z. (2014) Comparison of Time Development of the Sciatic Nerve Blockade Performed with 1\% Lidocaine Subgluteal and Popliteal Approach under Ultrasound Guidance. Open Journal of Anesthesiology, 4, 324-331. http://dx.doi.org/10.4236/ojanes.2014.412046 


\section{Guidance}

\section{Introduction}

It was expected that the use of ultrasound guidance in performing peripheral blockades could raise their efficiency to $100 \%$ [1]. But now different authors are reporting varying data on the effectiveness of regional blocks performed under ultrasound guidance: performance indicators vary from 80\% [1] to 100\% [2] [3]. The achievement of high efficiency is determined not only by the visualization of peripheral nerves, but also by the knowledge of the anatomical features of the peripheral nerve structure in its various departments which may influence the development of nerve blocks. The study by N. Moayeri et al. has demonstrated that in the proximal parts of the sciatic nerve, the ratio of non-neural and neural tissue is 2:1, whereas in the popliteal fossa, the ratio is $1: 1$ [4]. Probably the observed values may explain the differences seen in MEAV (minimum effective anesthetic volume) and in onset time at different levels of the sciatic nerve [4]. As indicated by N. Moayeri et al. their assumptions need clinical confirmation [4].

The matter under analysis involves conflicting data in the scientific literature. In the study by A. W. Kilpatrick et al., it is proved that the rate of the development of the sciatic nerve blockade performed with alkalinized 0.5\% bupivacaine with epinephrine (1:200,000) does not depend on the approach (classic gluteal approach or popliteal approach) [5]. M. Taboada et al. have found out that when the sciatic nerve is blocked with ropivacaine or mepivacaine sensory blocks develop faster when regional blockade of the sciatic nerve is performed in the proximal areas rather than in distal areas [6] [7].

There are no studies on the time of the development of regional anesthesia of the sciatic nerve in its proximal and distal parts with lidocaine.

The purpose of this study is to compare the time of peripheral blockade of the sciatic nerve with $1 \%$ lidocaine with epinephrine $(1: 200,000)$ carried out in subgluteal or popliteal areas under ultrasound guidance.

\section{Materials and Methods}

Before the operation the patients were randomized (random number generator) according to the approach to the blockade of the sciatic nerve (the name of the approach to the blockade of the sciatic nerve was sealed in the envelopes). To estimate the rate of anesthesia development according to the approach we grouped the patients: in Group A (20 patients) the sciatic nerve blockade was performed in subgluteal area with the introduction of 30 $\mathrm{ml}$ of 1\% lidocaine with epinephrine (1:200,000); in Group B (20 patients) the popliteal approach (30 ml of 1\% lidocaine with epinephrine $(1: 200,000)$ ) was implemented. In Group A blockades were performed for surgery of traumatic injuries and dysfunctions of shin bone, knee, ankle, foot, removal of metal from the shin bone. In Group B the blockades of the sciatic nerve were performed for surgery of ankle and foot.

The criteria for inclusion of patients in the study were surgical indication requiring anesthesia maintenance, patient's written consent about the type of anesthesia and possible complications of regional anesthesia. The exclusion criteria were patient's refusal of application of the proposed form of anesthesia, age $<18$ years, weight $<$ $50 \mathrm{~kg}$, physical status score for ASA > 3, a history of allergic reactions to drugs used, coagulopathy, infections of the skin at the injection site, neurological or neuro-muscle diseases, severe liver diseases, or kidney failures, obesity, inability to cooperate with the patient.

With the aim of premedication, 0.5 - $0.8 \mathrm{mg}$ of atropine and $10 \mathrm{mg}$ of Diphenhydramine were injected intramuscularly 20 - 30 min before the block. All patients exercised venous approach provided through a peripheral vein catheterization. SPO2, ECG and noninvasive blood pressure were monitored.

After a patient was placed in the prone position the blockade of the sciatic nerve was performed in subgluteal or popliteal areas under ultrasound guidance [8]. For visualization the ultrasound machine “Aloка SSC400" with the ultrasound transducer $7.5 \mathrm{MHz}$ was used. The studies show that in the subgluteal area the sciatic nerve is 3.2 $\mathrm{cm}$ distant from the skin and is approximately $5 \mathrm{~cm}$ distant from the skin in the region of the popliteal fossa. In this study the authors used the ultrasound frequency sensor with 7 - $13 \mathrm{MHz}$ [9]. After ultrasound visualization of the sciatic nerve a 100-mm insulated injection needle (Stimuplex ${ }^{\circledR}$, B Braun, Melsungen, Germany) connected to a nerve stimulator (HNS 11, B Braun, Melsungen, Germany) was applied to the sciatic nerve. The 
strength of the stimulation current was initially set at $0.4 \mathrm{~mA}$ (frequency $1 \mathrm{~Hz}$, pulse duration of 100 microseconds).

The blockade was performed with ultrasound guidance according to the technique "in plane". The strength of the stimulation current was initially set at $0.4 \mathrm{~mA}$ and remained unchanged during the whole procedure. Under ultrasound guidance the needle was applied to the fascial compartment of the sciatic nerve and the position of the end of the injection point was defined. Then the test dose of $0.5-1.0 \mathrm{ml}$ of local anesthetic was injected. The ultrasound image was used to assess the place of the solution introduction (intraneural or not). If necessary the position of the needle end was corrected under ultrasound guidance.

Under the ultrasound guidance the needle was applied to the nerve trunk until the muscle response of the appropriate muscle group. Upon the receipt of the muscle response after the aspiration test, the injection of local anesthetic in the fascial sheath of the sciatic nerve was carried out. Considering that the most effective blockade of the sciatic nerve in popliteal area [10] and subgluteal area [11] is reached in the propagation of local anesthetic along the entire circumference of the sciatic nerve, under the control of ultrasound imaging, if necessary, correction of the position of the injection needle to spread local anesthetic solution along the entire circumference of the sciatic nerve was carried out. An important factor for the time of closure of the popliteal sciatic nerve is the place of local anesthetic solution access (extrapareneural, intraparaneural, intraepinerual) [12]-[15]. We used the introduction of local anesthetic under the common epineural sheath. According to the data of Karmakar M. K. et al. the paraneural sheath was distinct from the epineurium, better delineated after the injection of local anesthetic, and enveloped not only the sciatic nerve but also the common peroneal and tibial nerves separately [15]. Figure 1 depicts the sciatic nerve in the popliteal fossa after administration of $30 \mathrm{ml}$ of local anesthetic. It can be seen that local anesthetic is distributed along the entire circumference of the sciatic nerve.

Figure 2 shows the same sciatic nerve distal to the injection point in the popliteal fossa. The sciatic nerve is divided into the common peroneal and tibial nerves. It should be noted that the solution of local anesthetic extends only along each nerve and extends along the entire circumference of each of them. These images display that the solution of local anesthetic is spread in the paraneural sheath which corresponds to the data provided by M. K. Karmakar et al. [15].

All blocks were performed by one anesthetist.

The introduction of the solution was defined as the zero point for time control. In all cases the patients undergoing limb surgery had additional blockades of the femoral nerve [8]. The blockade of the femoral nerve was performed with $1 \%$ lidocaine with $20 \mathrm{ml}$ of epinephrine addition (1:200,000). In one case $25 \mathrm{ml}$ of local anesthetic

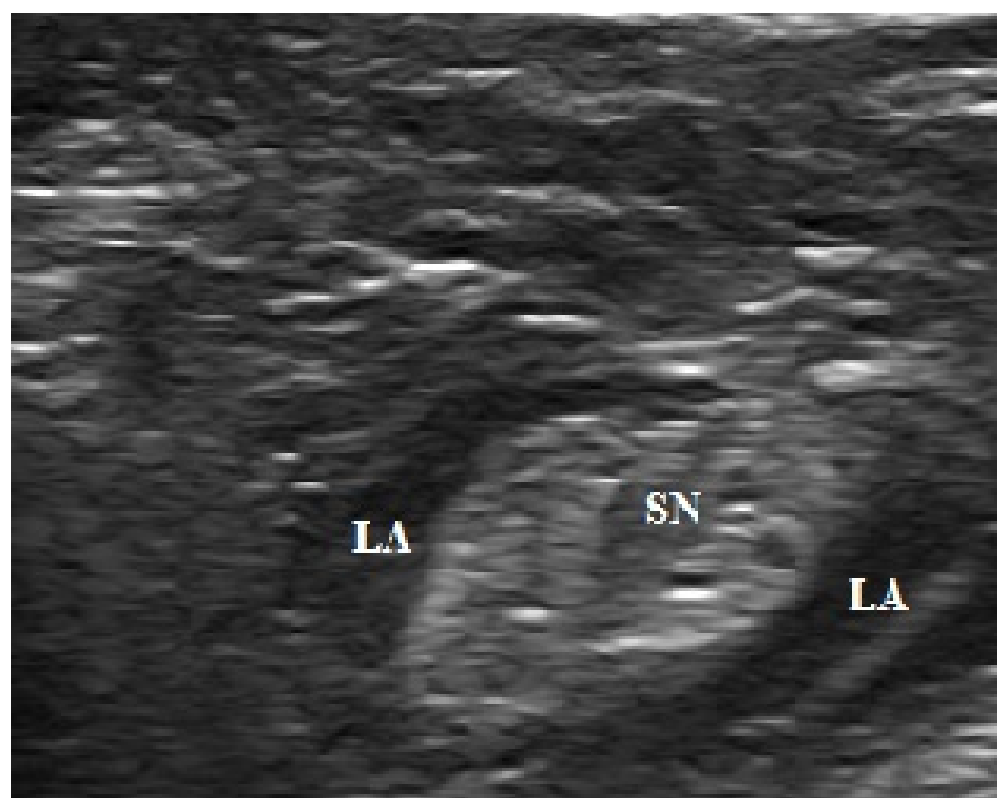

Figure 1. Sciatic nerve in the popliteal fossa after his $30 \mathrm{ml}$ of anesthetic blockade (prior to division): SN—sciatic nerve; LA —local anesthetic. Right lower limb. 


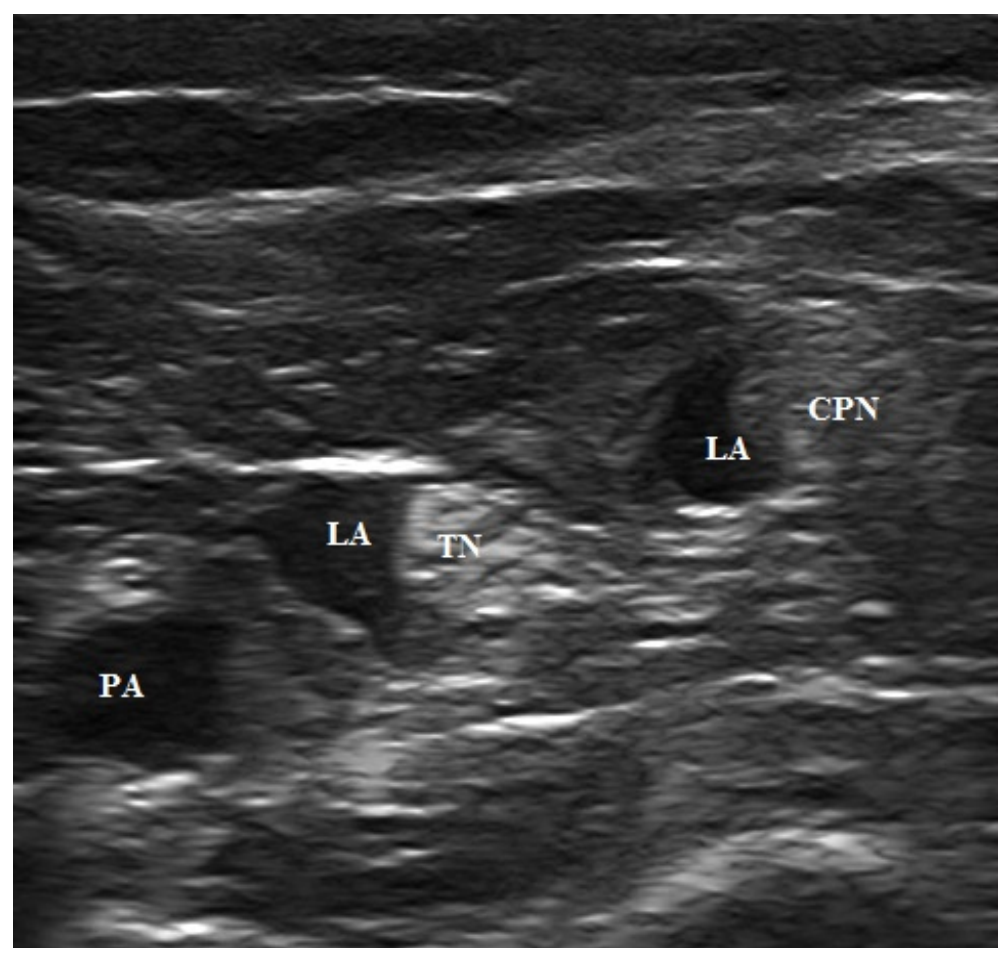

Figure 2. Spread of local anesthetic along the sciatic nerve (distal) in the popliteal fossa (after division): LA-local anesthetic; PA-popliteal artery; $\mathrm{TN}$ - tibial nerve; $\mathrm{CPN}$ - common peroneal nerve. The same patient. Right lower limb.

solution was used during the surgery to treat the arthroscopy of knee joint (Group A) The quality of the femoral nerve blockade or of the branches of the lumbar plexus (obturator, lateral femoral cutaneous nerve and femoral nerve) was evaluated once (after 25 minutes).

The primary endpoint was the time to develop a complete sensory block.

The evaluation of cutaneous sensitivity was carried out every 2 minutes up to 50 minutes of blockade in the zones of the innervation of the tibial and common peroneal nerves (reaction to prick). The following scale was used for sensory block assessment: "++" a complete sensory block (anesthesia); “+” an incomplete sensory block, the patient can not differentiate the type of irritant; "-" cutaneous sensitivity is fully preserved. The level of sensory block in the lower third of the leg, the middle and upper third of the leg was assessed as well. The evaluation of sensitivity was carried out by an independent anesthesiologist who was not involved in the study.

The secondary endpoint. The evaluation of motor block was carried out every 2 minutes up to 50 minutes after the injection of local anesthetic, using the following scale: "++" movements are totally absent; "+" movements are preserved partly or are not co-ordinated; "-” movements are fully preserved. A patient was asked to perform a plantar flexion of the foot (tibial nerve) and a flexion of the foot (common peroneal nerve). The evaluation of motor activity was carried out by an independent anesthesiologist who was not involved in the study.

All skin sensitivity tests and evaluation of motor block were performed prior to sedation. A few minutes after the start of surgery, for sedation, diazepam intravenously administered $10 \mathrm{mg}$ and/or $0.1 \mathrm{mg}$ of fentanyl, depending on the emotional state of the patient.

Statistical data processing was performed using the program Statistica 7.0. When choosing the number of patients in the groups we considered the data of P. Cuvillon et al. which show that it is enough to have 20 people in the group to conduct such research [16]. The primary endpoint was the time to complete the development of sensor unit. The comparison of two groups was performed using the nonparametric Mann-Whitney test. The data are presented as median and quartiles (25th and 75th percentiles). The differences between groups were considered statistically significant at $\mathrm{p}<0.05$.

The research was carried out with the permission of Ethics Committee at Health Care Institution "Mogilev Regional Hospital”, protocol No.3/C dated 2 Aug 2010. 


\section{Results}

In Group A (subgluteal approach) a complete sensory block (++) developed in 15 (14 - 16) minutes, in Group B (popliteal approach) a complete sensory block developed in 40 (38.5 - 42.5) minutes (Table 1). Thus, the development of a complete sensory block was faster in Group A compared with Group B. The groups displayed significant differences at $\mathrm{p}<0.01(\mathrm{p}=0.000)$. In Group A motor block in all cases was complete $(++)$ and developed during 15.5 (15 - 17) min. In Group B all patients’ motor block of the sciatic nerve was assessed as incomplete $(+)$.

In Group B the quality of sensory block ++ was defined at the level of the lower third of the leg, ankle and foot of 6 patients. In 14 patients the sensor unit ++ evolved within the foot, ankle, lower and middle third of the leg. In Group B the quality of sensory block ++ at all levels of the tibia was not noted. In Group B the level of sensory block of the sciatic nerve was sufficient to carry out surgery in the area of foot and ankle. Additional administration of analgesics during surgeries was not required.

In group A complete sensory block $(++)$ at all levels of the tibia was noted in all patients. In group A complete motor block occurred in all patients. Complications of anesthesia were not.

\section{Discussion}

In 2008, N. Moayeri et al. published a paper on the study of the quantitative architecture of the brachial plexus which suggests that the increase in the amount of connective tissue in the distal brachial plexus should lengthen the development of anesthesia performed in the distal parts in comparison with the blockade in the proximal part of the brachial plexus [17]. N. Moayeri et al. state that the use of large volumes of local anesthetic for brachial plexus block masks this effect [17]. The data received by S. Riazi et al. show slower development of motor and sensory blocks with a small volume of ropivacaine $(5 \mathrm{ml})$ compared with $20 \mathrm{ml}$ of ropivacaine for brachial plexus blockade [18] and thus confirm the hypothesis of N. Moayeri et al.

$\mathrm{N}$. Moayeri et al. hypothesize that the blockade of the sciatic nerve in the popliteal area requires a larger minimum dose of local anesthetic than the proximal blockade [4]. Probably, the observed values may explain the differences seen in minimum effective anesthetic volume (MEAV) and in onset time at different levels of the sciatic nerve [4]. As indicated by N. Moayeri et al., their assumptions need clinical confirmation [4]. It is also suggested that the time of development of anesthesia for the same amount of local anesthetic should lengthen when the distal blockade is being performed because connective tissue is the main obstacle to the diffusion of anesthetic to axons [4]. Indirectly, the hypothesis by N. Moayeri et al. about the amount of connective tissue as the principal obstacle to the diffusion of local anesthetic blocking the sciatic nerve was previously confirmed in our study where we proved that while performing the posterior blockade of the sciatic nerve under ultrasound guidance the reduction of the amount of $0.75 \%$ ropivacaine solution from $10 \mathrm{ml}$ to $5 \mathrm{ml}$ significantly increases

Table 1. Characteristics of the groups under study.

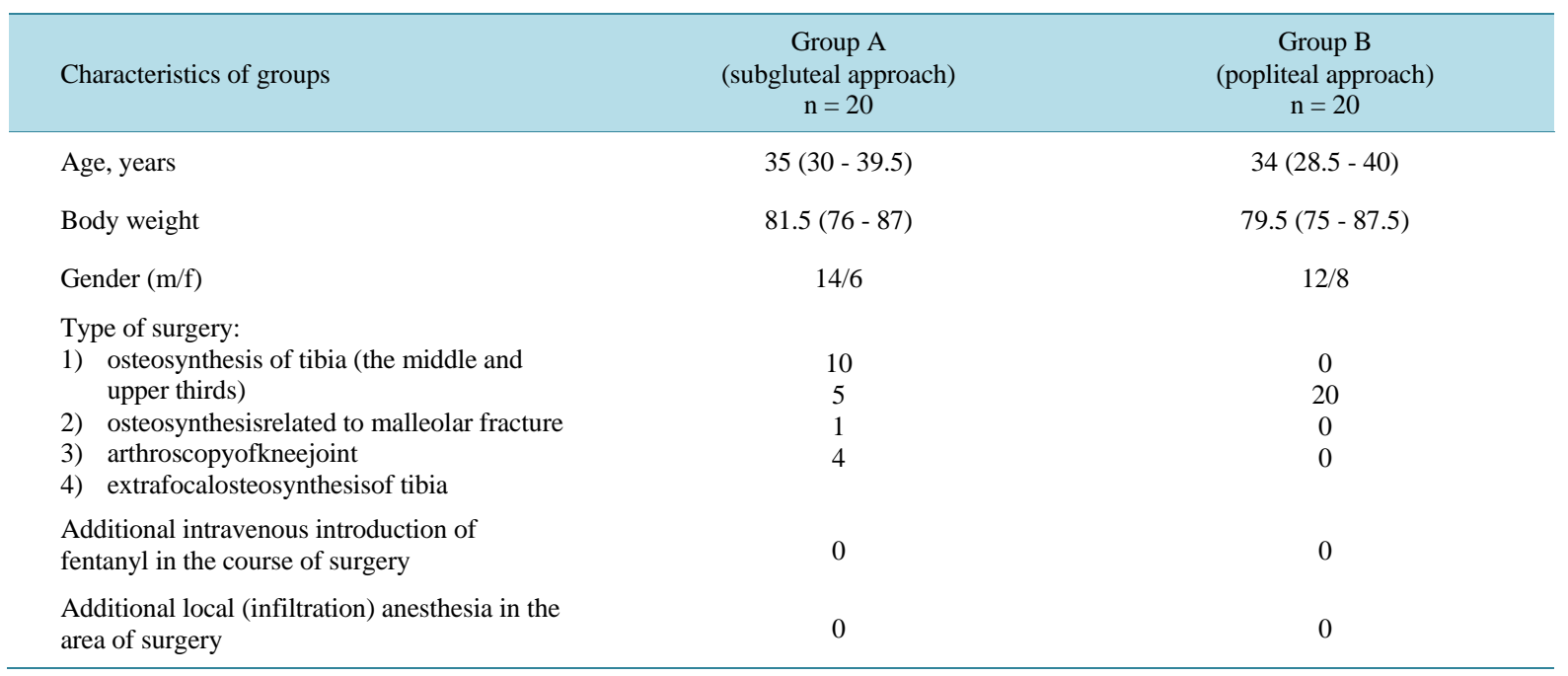


the time of the development of complete sensory and motor blocks [19].

Our data acquired for lidocaine confirm the results obtained by M. Taboada et al. for ropivacaine and mepivacaine which indicated the increase of the time of the popliteal sciatic nerve blockade [6] [7]. It should be noted that in all of the studies performed blockade efficiency was low and required additional pain relief for patients during surgery [5]-[7]. This, in our opinion, is due to the implementation of blocks without using ultrasound imaging. The study by S. Robards et al. using ultrasound guidance states that when applying electrical stimulation of the sciatic nerve in the popliteal fossa in $83 \%$ cases motor block was obtained with the intraneural injection of local anesthetic [20]. All patients in the study group provided motor responses to the stimulation by the current of $0.4 \mathrm{~mA}$ and the subsequent ultrasound images indicated intraneural administration of local anesthetic solution [20]. As in the studies by M. Taboada et al. ultrasound visualization was not used we cannot exclude intraneural administration of local anesthetic which led not only to the development of a complete motor block but also determined faster development of anesthesia while performing the popliteal sciatic nerve blockade with $0.75 \%$ ropivacaine solution $(26 \pm 10 \mathrm{~min}$ ) [5] in contrast to our study where the application of $30 \mathrm{ml}$ of $1 \%$ lidocaine during the development of sensory block was 40 (38.5 - 42.5) min. In our study we used electrical power of $0.4 \mathrm{~mA}$. It does not allow the exclusion of the intraneural administration of local anesthetics, but the use of ultrasound guidance helps to avoid intraneural injection of local anesthetic.

The data obtained by M. Taboada et al. [21] demonstrate that the blockade of the sciatic nerve in the popliteal fossa with $20 \mathrm{ml}$ of $0.75 \%$ ropivacaine evolved longer $(26 \pm 10 \mathrm{~min}$ ) than while applying the rear approach (Labat) (12 $\pm 6 \mathrm{~min}$ ). But these figures contradict the data obtained by P. Cuvillon $e t$ al. whoshowed that in case with the blockade of the sciatic nerve in accordance with the rear approach with $20 \mathrm{ml}$ of $0.75 \%$ ropivacaine a complete block developed in 40 minutes [16].

Our results do not correspond to the data obtained by A. W. Kilpatrick et al. who did not get any time differences of blockade [5]. Therefore the data obtained by A. W. Kilpatrick et al. may be questioned because effective anesthesia of the patients in the popliteal area was 9 effective blockades out of 20 [5]. This poor performance is linked to the inability to control the spread of local solution along the entire circumference of the sciatic nerve, and this, according to the earlier obtained data, provides the highest efficiency of the sciatic nerve blockade [10] [11].

The data acquired by R.Seidel confirm that the introduction of local anesthetic under the epinevry of the sciatic nerve (popliteal access) involves faster developing anesthesia than the introduction of local anesthetic extraparaneuraly [22]. Although in this paper the introduction of anesthetic subparaneuraly ("subepimyseal perineural compartment”) is not discussed, it is described in other studies [15].

$\mathrm{N}$. Moayeri et al. note that the findings of the architectural features of the sciatic nerve at its various sites and the assumption about the impact of the anatomy of the sciatic nerve on the time of the development of anesthesia should be cautiously extrapolated to the clinical area [4]. In our opinion, M. Taboada's results and our data allow to extrapolate N. Moayeri's et al. results to clinical practice more precisely and boldly.

According to $\mathrm{N}$. Moaeri et al. in the popliteal fossa in the deep layers of the sciatic nerve more neural fibers and adipose tissue contain which slow down the diffusion of local anesthetic [4]. These factors might result in a later onset of anesthesia in Group B (popliteal access). Nonneural tissue also serves as a reservoir for lipophilic local anesthetics which requires more local anesthetic for the development of anesthesia [4] [17]. In our opinion, in our study the absence of a complete motor block in Group B (popliteal access) is related to the use of $30 \mathrm{ml}$ of $1 \%$ lidocaine (probably needs more research).

S. Riazi et al. stateth at the use of a smaller volume of $0.5 \%$ lidocaine solution $(5 \mathrm{ml})$ in comparison with 20 $\mathrm{ml}$ is accompanied by the increased time of the peripheral block development [18]. At the same time P. Gautier et al. have found out that the time of the development of the blockade of the brachial plexus by the interscalene access with $20 \mathrm{ml}$ and $5 \mathrm{ml}$ of $0.75 \%$ ropivacaine solution is not changed [23]. In the study of S. Riazi et al. general anesthesia was applied which makes it difficult to assess the development of the blockade. In these studies different levels of the brachial plexus block are used: in the research by S. Riazi et al. roots level-one injection; in the study of P. Gautier et al. level of trunks of three injections; S. Riazi et al. evaluate postoperative analgesia, P. Gautier et al.- surgical anesthesia [18] [23]. Thus, these data are contradictory and can hardly be compared. González et al. consider that in case with the blockade of the brachial plexus by the supraclavicular access with various volumes of lidocaine but with the same amount $(\mathrm{mg})$ of local anesthetic there is no difference in the time of the peripheral blockade development [24]. In this study the reduction of local anesthetic is absent and probably this fact influenced the absence of time difference in the development of anesthesia. In 
other studies when there was a decrease not only of the volume but also of the amount of local anesthetic for the sciatic nerve blockade there was a difference in time [11]. There are no studies that would compare the time of closure of the brachial plexus with the application of different approaches of one and the same volume and amount of local anesthetic.

The reason of an incomplete blockade of the sciatic nerve in group B was probably the change of the ratio "non-neural and neural tissue" towards the increase of the non-neural tissue of the sciatic nerve. But one of the factors affecting the quality of blockade is the place of the access of local anesthetic (extraparaneural, intra paraneural, intraepinerual) [12]-[15]. The fascial cover of the sciatic nerve in the popliteal space has a very thinanatomic structure and ultrasound guidance does not allow its differentiation yet. It is not improbable that an incomplete motor block was caused by the extraparaneural introduction of local anesthetic. But in this case it is not quite right to state that in all cases under the study it was caused by the extraparaneural introduction of local anesthetic because the results of the blockades in the group turned out to be comparable according to their effect. The opportunity to define the place of the introduction of local anesthetic in our research is limited.

For the study we opted for the local anesthetic lidocaine as the most accessible and cheapest local anesthetic which also has the least effect on ischemic peripheral nerves [25]. In one case in group A the total amount of lidocaine was $550 \mathrm{mg}$ exceeding the admissible amount by $50 \mathrm{mg}$. It did not involve any complications. As noted by P. Cuvillon et al. such an excess of the local anesthetic dose does not lead to any toxic effect [16].

The existing deficiencies in the study include the impossibility of complete blindness. The anesthesiologist who performed the sciatic nerve blockade knew about the access, the anesthesiologist who rated the quality of the blockade did not know about the study and did not know about the access to the sciatic nerve.

When you select the level of blockade of the sciatic nerve should take into account the level of anesthetic blockade popliteal access. Also worth noting is a longer time of anesthesia of the sciatic nerve from the popliteal access. It can deliver some inconveniences of the surgical team in the form of a long wait.

\section{Conclusion}

In conclusion, it should be mentioned that this is the first study which involves the comparison of the time of the development of sensory block of the sciatic nerve with $1 \%$ lidocaine with epinephrine $(1: 200,000)$ in subgluteal and popliteal areas under ultrasound guidance. A significant prolongation of the time of the development of sensory block of the sciatic nerve up to 40 (38.5 - 42.5) minutes in the popliteal fossa in comparison with infragluteal approach-15 (14 - 16) minutes has been registered. Complete motor blocks of the sciatic nerve were noted for none of the patients.

\section{References}

[1] Marhofer, P., Harrop-Griffiths, W., et al. (2010) Fifteen Years of Ultrasound Guidance in Regional Anaesthesia: Part 1. British Journal of Anaesthesia, 104, 538-546. http://dx.doi.org/10.1093/bja/aeq069

[2] Marhofer, P., Greher, M. and Kapral, S. (2005) Ultrasound Guidance in Regional Anaesthesia. British Journal of Anaesthesia, 94, 7-17. http://dx.doi.org/10.1093/bja/aei002

[3] Piacherski, V., Marochkov, A., Brukhnou, A. and Kokhan, Z. (2012) Comparison of Three Methods of Regional Anesthesia of Peripheral Nerves and Plexuses. Open Journal of Anesthesiology, 2, 237-243. http://dx.doi.org/10.4236/ojanes.2012.25056

[4] Moayeri, N. and Groen, G.J. (2009) Differences in Quantitative Architecture of Sciatic Nerve May Explain Differences in Potential Vulnerability to Nerve Injury, Onset Time, and Minimum Effective Anesthetic Volume. Anesthesiology, 111, 1128-1134. http://dx.doi.org/10.1097/ALN.0b013e3181bbc72a

[5] Kilpatrick, A.W., Coventry, D.M. and Todd, J.G. (1992) A Comparison of Two Approaches to Sciatic Nerve Block. Anaesthesia, 47, 155-157. http://dx.doi.org/10.1111/j.1365-2044.1992.tb02018.x

[6] Taboada, M., Rodriguez, J., Del Rio, S., Lagunilla, J., Carceller, J., Alvarez, J. and Atanassoff, P.G. (2005) Does the Site of Injection Distal to the Greater Trochanter Make a Difference in Lateral Sciatic Nerve Blockade? Anesthesia \& Analgesia, 101, 1188-1191. http://dx.doi.org/10.1213/01.ane.0000172289.83180.2e

[7] Taboada, M., Alvarez, J., Cortes, J., Rodriguez, J., Rabanal, S., Gude, F., Atanassoff, A. and Atanassoff, P.G. (2004) The Effects of Three Different Approaches on the Onset Time of Sciatic Nerve Blocks with 0.75\% Ropivacaine. Anesthesia \& Analgesia, 98, 242-247. http://dx.doi.org/10.1213/01.ANE.0000093311.29111.59

[8] Perlas, A., Brull, R., Chan, V.W., McCartney, C.J., Nuica, A. and Abbas, S. (2008) Ultrasound Guidance Improves the Success of Sciatic Nerve Block at the Popliteal Fossa. Regional Anesthesia and Pain Medicine, 33, 259-265. 
http://dx.doi.org/10.1016/j.rapm.2007.10.010

[9] Bruhn, J., Van Geffen, G.J., Gielen, M.J. and Scheffer, G.J. (2008) The Value of Ultrasonography for Performing Peripheral Nerve Blocks. Acta Anaesthesiologica Scandinavica, 52, 1298-1302. http://dx.doi.org/10.1111/j.1399-6576.2008.01695.x

[10] Brull, R., Macfarlane, A.J., Parrington, S.J., Koshkin, A. and Chan, V.W. (2011) Is Circumferential Injection Advantageous for Ultrasound-Guided Popliteal Sciatic Nerve Block? A Proof-of-Concept Study. Regional Anesthesia \& Pain Medicine, 36, 266-270. http://dx.doi.org/10.1097/AAP.0b013e318217a6a1

[11] Piacherski, V. and Marachkou, A. (2014) Features and Principles the Spread of Local Anesthetic Blockade of the Sciatic Nerve at Depends on the Amount of Anesthetic. Open Journal of Anesthesiology, 4, 31-35. http://dx.doi.org/10.4236/ojanes.2014.42004

[12] Andersen, H.L., Andersen, S.L. and Tranum-Jensen, J. (2012) Injection inside the Paraneural Sheath of the Sciatic Nerve: Direct Comparison among Ultrasound Imaging, Macroscopic Anatomy, and Histologic Analysis. Regional Anesthesia and Pain Medicine, 37, 410-414. http://dx.doi.org/10.1097/AAP.0b013e31825145f3

[13] Perlas, A., Wong, P., Abdallah, F., Hazrati, L.N., Tse, C. and Chan, V. (2013) Ultrasound-Guided Popliteal Block through a Common Paraneural Sheath versus Conventional Injection: A Prospective, Randomized, Double-Blind Study. Regional Anesthesia and Pain Medicine, 38, 218-225. http://dx.doi.org/10.1097/AAP.0b013e31828db12f

[14] Vloka, J.D., Hadzić, A., Lesser, J.B., Kitain, E., Geatz, H., April, E.W. and Thys, D.M. (1997) A Common Epineural Sheath for the Nerves in the Popliteal Fossa and Its Possible Implications for Sciatic Nerve Block. Anesthesia \& Analgesia, 84, 387-390.

[15] Karmakar, M.K., Shariat, A.N., Pangthipampai, P. and Chen, J. (2013) High-Definition Ultrasound Imaging Defines the Paraneural Sheath and the Fascial Compartments Surrounding the Sciatic Nerve at the Popliteal Fossa. Regional Anesthesia and Pain Medicine, 38, 447-451. http://dx.doi.org/10.1097/AAP.0b013e31829ffcb4

[16] Cuvillon, P., Nouvellon, E., Ripart, J., Boyer, J.C., Dehour, L., Mahamat, A., L’hermite, J., Boisson, C., Vialles, N., Lefrant, J.Y. and de La Coussaye, J.E. (2009) A Comparison of the Pharmacodynamics and Pharmacokinetics of Bupivacaine, Ropivacaine (with Epinephrine) and Their Equal Volume Mixtures with Lidocaine Used for Femoral and Sciatic Nerve Blocks: A Double-Blind Randomized Study. Anesthesia \& Analgesia, 108, 641-649. http://dx.doi.org/10.1213/ane.0b013e31819237f8

[17] Moayeri, N., Bigeleisen, P.E. and Groen, G.J. (2008) Quantitative Architecture of the Brachial Plexus and Surrounding Compartments, and Their Possible Significance for Plexus Blocks. Anesthesiology, 108, 299-304. http://dx.doi.org/10.1097/01.anes.0000299433.25179.70

[18] Riazi, S., Carmichael, N., Awad, I., Holtby, R.M. and McCartney, C.J. (2008) Effect of Local Anaesthetic Volume (20 vs $5 \mathrm{ml}$ ) on the Efficacy and Respiratory Consequences of Ultrasound-Guided Interscalene Brachial Plexus Block. British Journal of Anaesthesia, 101, 549-556. http://dx.doi.org/10.1093/bja/aen229

[19] Valery, P. and Aliaksei, M. (2013) A Comparison of the Onset Time of Complete Blockade of the Sciatic Nerve in the Application of Ropivacaine and Its Equal Volumes Mixture with Lidocaine: A Double-Blind Randomized Study. Korean Journal of Anesthesiology, 65, 42-47. http://dx.doi.org/10.4097/kjae.2013.65.1.42

[20] Robards, C., Hadzic, A., Somasundaram, L., Iwata, T., Gadsden, J., Xu, D. and Sala-Blanch, X. (2009) Intraneural Injection with Low-Current Stimulation during Popliteal Sciatic Nerve Block. Anesthesia \& Analgesia, 109, 673-637. http://dx.doi.org/10.1213/ane.0b013e3181aa2d73

[21] Taboada, M., Rodríguez, J., Álvarez, J., Cortés, J., Gude, F. and Atanassoff, P.G. (2004) Sciatic Nerve Block via Posterior Labat Approach Is More Efficient Than Lateral Popliteal Approach Using a Double-Injection Technique: A Prospective, Randomized Comparison. Anesthesiology, 101, 138-142. http://dx.doi.org/10.1097/00000542-200407000-00022

[22] Seidel, R., Natge, U. and Schulz, J. (2013) Distal Sciatic Nerve Blocks: Randomized Comparison of Nerve Stimulation and Ultrasound Guided Intraepineural Block. Der Anaesthesist, 62, 183-192. http://dx.doi.org/10.1007/s00101-013-2150-5

[23] Gautier, P., Vandepitte, C., Ramquet, C., DeCoopman, M., Xu, D. and Hadzic, A. (2011) The Minimum Effective Anesthetic Volume of $0.75 \%$ Ropivacaine in Ultrasound-Guided Interscalene Brachial Plexus Block. Anesthesia \& Analgesia, 113, 951-955.

[24] González, A.P., Bernucci, F., Techasuk, W., Pham, K., Finlayson, R.J. and De Tran, Q.H. (2013) A Randomized Comparison between 3 Combinations of Volume and Concentration of Lidocaine for Ultrasound-Guided Infraclavicular Block. Regional Anesthesia and Pain Medicine, 38, 206-211.

[25] Bouaziz, H., Iohom1, G., Estèbe, J.P., Campana, W.M. and Myers, R.R. (2005) Effects of Levobupivacaine and Ropivacaine on Rat Sciatic Nerve Blood Flow. British Journal of Anaesthesia, 95, 696-700. http://dx.doi.org/10.1093/bja/aei242 
Scientific Research Publishing (SCIRP) is one of the largest Open Access journal publishers. It is currently publishing more than 200 open access, online, peer-reviewed journals covering a wide range of academic disciplines. SCIRP serves the worldwide academic communities and contributes to the progress and application of science with its publication.

Other selected journals from SCIRP are listed as below. Submit your manuscript to us via either submit@scirp.org or Online Submission Portal.
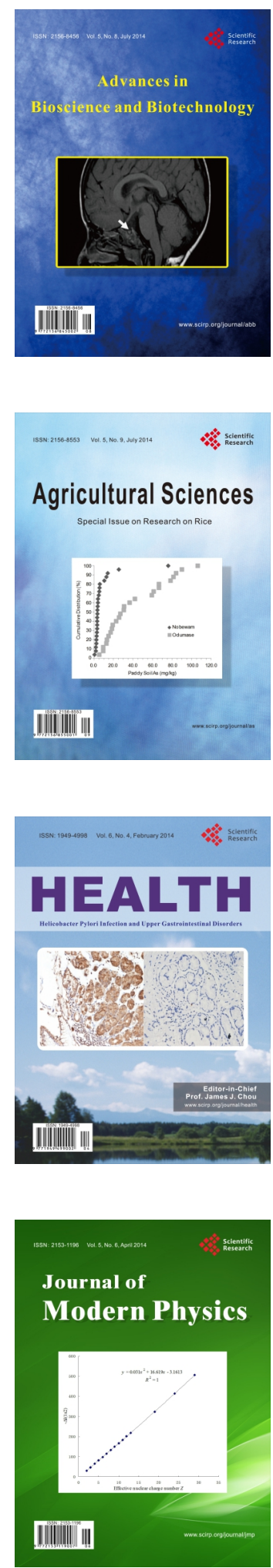
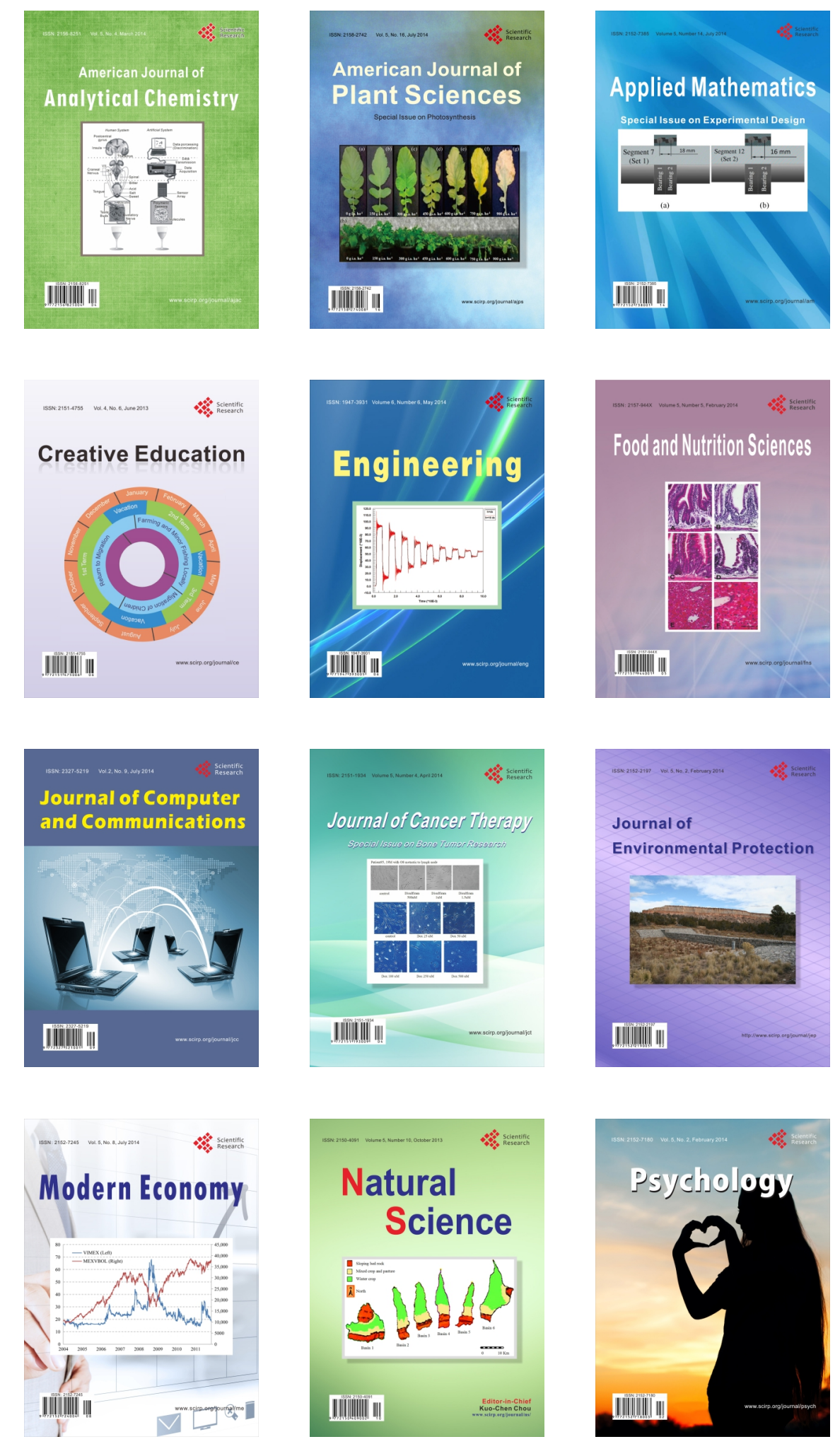